\title{
Effects of Advanced Oxidation Processes on the Decomposition Properties of Organic Compounds with Different Molecular Structures in Water
}

\author{
Harufumi Suzuki, Shoichi Yamagiwa, Sadao Araki, Hideki Yamamoto* \\ Department of Chemical, Energy and Environmental Engineering, Faculty of Environmental and Urban \\ Engineering, Kansai University, Osaka, Japan \\ Email: k231927@kansai-u.ac.jp, "yhideki@kansai-u.ac.jp
}

Received 2 June 2016; accepted 23 July 2016; published 27 July 2016

Copyright (C) 2016 by authors and Scientific Research Publishing Inc.

This work is licensed under the Creative Commons Attribution International License (CC BY). http://creativecommons.org/licenses/by/4.0/

(c) $\underset{\mathrm{EY}}{\mathrm{P}}$ Open Access

\section{Abstract}

Studies to decompose persistent organic pollutants in wastewater from chemical factories by using Advanced Oxidation Processes (AOPs) have recently been performed. Oxidation reactions involving ozone and $\bullet \mathrm{OH}$ radicals and cleavage caused by $\mathrm{UV}$ are the main decomposition reactions that occur in AOPs using ozone and UV. The mechanisms through which organic compounds are decomposed in AOPs are complicated and difficult to understand because various decomposition reactions occur simultaneously. The Total Organic Carbon (TOC) removal efficiencies achieved in several different AOPs were evaluated in this study. The TOC removal efficiencies were different for organic compounds with different chemical structures. The TOC was more effectively removed when aromatic compounds were treated using the $\mathrm{O}_{3}-\mathrm{UV}-\mathrm{TiO}_{2}$ process than when using the other AOPs, and the TOC was removed more effectively by the $\mathrm{O}_{3}-\mathrm{UV}$ process than by the $\mathrm{UV}-\mathrm{TiO}_{2}$ process. However, the TOC was removed more effectively when open-chain compounds were treated using the $\mathrm{UV}-\mathrm{TiO}_{2}$ process than using the $\mathrm{O}_{3}-\mathrm{UV}$ process, and the $\mathrm{UV}-\mathrm{TiO}_{2}$ and $\mathrm{O}_{3}-\mathrm{UV}-\mathrm{TiO}_{2}$ processes resulted in similar TOC removal efficiencies. Therefore, it is necessary to use the $\mathrm{O}_{3}-\mathrm{UV}-\mathrm{TiO}_{2}$ process to decompose aromatic compounds as quickly as possible. On the other hand, the $\mathrm{UV}-\mathrm{TiO}_{2}$ process degraded the open-chain compounds most effectively, and the $\mathrm{O}_{3}-\mathrm{UV}-\mathrm{TiO}_{2}$ process did not need to decompose open-chain compounds. Moreover, the TOC of aromatic compounds was removed more slowly than that of open-chain compounds. The TOC removal efficiency increased with decreasing the number of carbon atoms in the molecule. The TOC removal efficiencies increased in order of the organic compounds containing methyl groups, aldehyde groups and carboxyl groups. The removal of the TOC when organic compounds were treated using the $\mathrm{O}_{3}$-UV-TiO ${ }_{2}$ process followed pseudo-zero-order kinetics.

\footnotetext{
*Corresponding author.
} 


\section{Keywords}

\section{Advanced Oxidation Process, Ozone, Hydroxyl Radical, Decomposition Efficiency, Water Treatment}

\section{Introduction}

Persistent organic pollutants in industrial wastewater cause serious pollution problems in the aquatic environment [1]. Some persistent organic pollutants are very toxic and are hazardous to the health of humans and other biota. Persistent organic pollutants are poorly biodegradable, meaning that natural processes cause very little decomposition of these compounds to occur, so these compounds can pollute the environment for a long time. Water is currently widely treated using activated sludge or activated carbon or using solid-liquid separation methods, but it is difficult to completely decompose persistent organic pollutants using these methods [2]-[6]. Attention has recently been paid to the use of advanced oxidation processes (AOPs) to remove persistent organic pollutants from water.

The oxidative decomposition of organic pollutants in wastewater can be achieved in an AOP by producing hydroxyl $(\bullet \mathrm{OH})$ radicals using a combination of ozone, ultraviolet light (UV), semiconductor photocatalysts, hydrogen peroxide, ultrasound, and Fenton reagents [7]. The oxidation-reduction potential of the $\bullet \mathrm{OH}$ radical is $2.85 \mathrm{eV}$, which is higher than the oxidation-reduction potentials of ozone (2.07 eV), hydrogen peroxide (1.77 $\mathrm{eV})$, and hypochlorous acid $(1.49 \mathrm{eV})$ [8]. Therefore, $\bullet \mathrm{OH}$ radicals are very reactive, and it is theoretically possible for $\bullet \mathrm{OH}$ radicals to decompose almost all organic compounds to give inorganic products, such as water and carbon dioxide. $\bullet \mathrm{OH}$ radicals cannot exist for very long under normal environmental conditions.

Ozone is a strong oxidizing agent that is highly selective toward specific organic compounds, such as unsaturated compounds [9]. Ozone decomposes spontaneously and then forms oxygen, so the secondary treatment of wastewater that has been treated with ozone is unnecessary, and the treated wastewater poses little risk to the environment. Additionally, UV can be used to decompose organic compounds because UV with a wavelength of less than $287 \mathrm{~nm}$ can cleave organic C-H bonds [10].

A large proportion of AOP studies have been performed using ozone-hydrogen peroxide-UV processes [11] [12], ozone-semiconductor photocatalyst processes [13], and AOPs based on the Fenton reaction [14]-[16]. Combinations of ozone and UV have often been used to decompose organic compounds because such combinations can remove a wide range of pollutants [17].

The decomposition of organic compounds in an AOP using ozone and UV will mainly involve oxidation by ozone and $\bullet \mathrm{OH}$ radicals and cleavage by UV [18]. The mechanisms through which organic compounds are decomposed in AOPs are complicated and difficult to understand because various decomposition reactions occur simultaneously. It is thought that the efficiencies with which organic compounds are decomposed in an AOP depends on the chemical structures of the organic compounds and the AOP conditions. However, it has been reported about decomposition of various organic compounds using AOP, but there have been relatively few studies of the decomposition efficiencies achieved for compounds with different structures under different AOP conditions [19]. Therefore, we have been studied about the effects of AOPs on the decomposition properties of organic compounds with different structures.

In this study, we confirmed that the decomposition efficiencies achieved in an AOP are influenced by the AOP conditions and the chemical structures of the organic compounds being decomposed. We examined the influence of the AOP conditions on the decomposition efficiency achieved by performing tests using different AOPs (using ozone, $\mathrm{UV}$, and $\mathrm{TiO}_{2}$ to generate $\bullet \mathrm{OH}$ radicals) but the same organic compounds. We examined the influence of the chemical structure on the decomposition efficiency achieved by performing tests using an $\mathrm{O}_{3}$ $\mathrm{UV}-\mathrm{TiO}_{2}$ process and different organic compounds.

\section{Experimental}

The experiments were carried out in a double-tube glass reactor. The inner and outer tubes had inner diameters of 22.0 and $40.0 \mathrm{~mm}$, respectively, and the volume of the space between the tubes was $230 \mathrm{~cm}^{3}$. Both tubes were made of quartz glass. A photograph of the AOP reactor is shown in Figure 1. The sample solution was fed into the space between the inner and outer tubes. The volume between the point at which the ozone came into contact with the sample solution and the AOP reactor was $45.0 \mathrm{~cm}^{3}$. A low-pressure mercury lamp (UVL-10DS-33; 


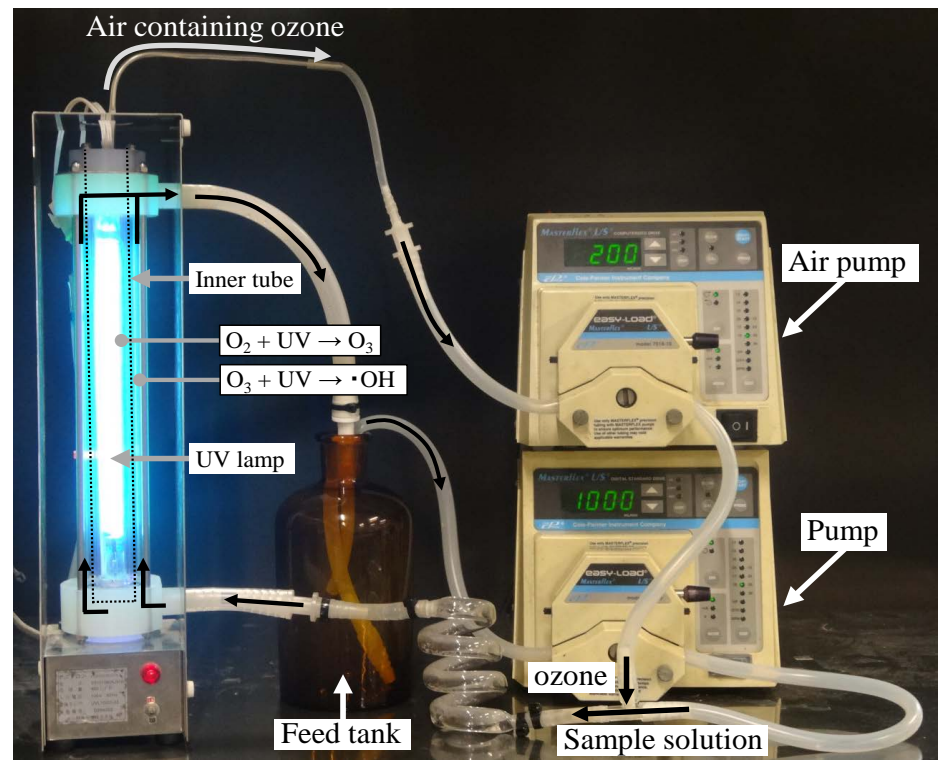

Figure 1. Photograph of the advanced oxidation process reactor.

SEN Lights Co., Osaka, Japan) was placed in the middle of the reactor to act as a UV source. The UV lamp had a power output of $10.5 \mathrm{~W}$, and the predominant wavelengths produced were 185 and $254 \mathrm{~nm}$. The air in the inner tube and the sample solution in the space between the inner and outer tubes were simultaneously irradiated by the UV lamp. Ozone has usually been generated using the silent electrical discharge method in other studies [20], but this method consumes large amounts of electricity [21] [22]. Ozone was therefore generated in our study using the Chapman method [23] [24], which consumed relatively little energy. Ozone was generated in the inner tube by UV irradiation, expressed by

$$
\begin{gathered}
\mathrm{O}_{2}+h v \rightarrow 2 \mathrm{O}(\lambda=175-242 \mathrm{~nm}) \\
\mathrm{O}+\mathrm{O}_{2}+\mathrm{M} \rightarrow \mathrm{O}_{3}+\mathrm{M}
\end{gathered}
$$

where $\mathrm{M}$ is the extra energy absorber which doesn’t participate in a chemical reaction directly. $\mathrm{M}$ is any molecule in the atmosphere, and $\mathrm{M}$ is usually another $\mathrm{O}_{2}$ or $\mathrm{N}_{2}$ [23] [24]. When an oxygen molecule is irradiated with UV light (wavelength 175 - $242 \mathrm{~nm}$ ), the oxygen molecule dissociates to ground-state oxygen atoms; a groundstate oxygen atom reacts with an oxygen molecule in the presence of a third reactant such as a coexistent gas (M), and ozone is generated. The coexistent gas is not directly involved in the reaction, but it is used to absorb the excess energy generated by ozone formation [25].

The generated ozone was transferred by an air pump (MASTER FLEX 7523-40; Cole-Parmer Instrument Co., Vernon Hills, IL, USA) through a stainless steel pipe from the inner tube to the sample solution. Ozone was produced continually because the top part of the inner tube was open to the air. Some of the ozone would have dissolved in the sample solution and been transferred to the outer tube with the sample solution. $\bullet \mathrm{OH}$ radicals were generated by irradiating ozone in the aqueous solution between the inner tube and the outer tube with UV at a wavelength $<310 \mathrm{~nm}$ [26]-[30], expressed by

$$
\begin{gathered}
\mathrm{O}_{3}+h v(\lambda<310 \mathrm{~nm}) \rightarrow \mathrm{O}_{2}+\mathrm{O} \\
\mathrm{O}+\mathrm{H}_{2} \mathrm{O} \rightarrow 2 \cdot \mathrm{OH}
\end{gathered}
$$

The generated $\bullet \mathrm{OH}$ radicals approach each other and become surrounded by water clusters; the $\bullet \mathrm{OH}$ radicals are bound immediately, by the cage effect, and then hydrogen peroxide is generated [27]-[30].

$$
\begin{gathered}
2 \cdot \mathrm{OH} \rightarrow \mathrm{H}_{2} \mathrm{O}_{2} \\
\mathrm{H}_{2} \mathrm{O}_{2}+\mathrm{O}_{3} \rightarrow \cdot \mathrm{OH}
\end{gathered}
$$

Ozone is unstable in solution, and $\bullet \mathrm{OH}$ radicals are generated by an autolytic process [30]. 


$$
\begin{gathered}
\mathrm{O}_{3}+\mathrm{OH}^{-} \rightarrow \mathrm{HO}_{2}^{-}+\mathrm{O}_{2} \\
\mathrm{O}_{3}+\mathrm{HO}_{2}^{-} \rightarrow \mathrm{O}_{3}^{-}+\mathrm{HO}_{2} \\
\mathrm{O}_{3}^{-}+\mathrm{H}^{+} \rightarrow \mathrm{HO}_{3} \\
\mathrm{HO}_{3} \rightarrow \cdot \mathrm{OH}+\mathrm{O}_{2} \\
\mathrm{O}_{3}^{-}+\left(\mathrm{H}_{2} \mathrm{O}\right) \rightarrow \cdot \mathrm{OH}+\mathrm{O}_{2}+\mathrm{OH}^{-}
\end{gathered}
$$

The outer tube was able to be replaced with a tube that was coated on the inside with a photocatalyst. The photocatalyst used was $\mathrm{TiO}_{2}$, which is chemically stable and relatively harmless. The $\mathrm{TiO}_{2}$ coating was applied using a dip-coating sol-gel method [31]. The $\mathrm{TiO}_{2}$ sol contained $\left[\left(\mathrm{CH}_{3}\right)_{2} \mathrm{CHO}\right]_{4} \mathrm{Ti}$, anhydrous $\mathrm{C}_{2} \mathrm{H}_{5} \mathrm{OH}$, distilled water, and $\mathrm{HCl}$ at a $\left[\left(\mathrm{CH}_{3}\right)_{2} \mathrm{CHO}\right]_{4} \mathrm{Ti}$ : anhydrous $\mathrm{C}_{2} \mathrm{H}_{5} \mathrm{OH}$ : distilled water: $\mathrm{HCl}$ molar ratio of 0.100:0.800: 0.100:0.00800. The inside of the outer tube was dip-coated with the $\mathrm{TiO}_{2}$ sol, then the tube was dried at room temperature for $10 \mathrm{~min}$ and then calcined at $923 \mathrm{~K}$. The tube was analyzed by X-ray diffractometry, and this confirmed that the $\mathrm{TiO}_{2}$ film produced was entirely in the anatase phase. The $\mathrm{O}_{3}-\mathrm{UV}-\mathrm{TiO}_{2}$ and $\mathrm{UV}-\mathrm{TiO}_{2}$ processes were performed using the outer tube that had been coated with $\mathrm{TiO}_{2}$. Irradiating $\mathrm{TiO}_{2}$ with $\mathrm{UV}$ at a wavelength of $<400 \mathrm{~nm}$ causes oxidation-reduction reactions to occur, allowing organic compounds to be decomposed.

\begin{tabular}{|c|c|c|c|c|c|}
\hline & Molecular structure & $\begin{array}{l}\text { Chemical } \\
\text { formula }\end{array}$ & Molecular weight & $\begin{array}{c}\text { Initial } \\
\text { concentration }\end{array}$ & Initial TOC \\
\hline Catechol & & $\mathrm{C}_{6} \mathrm{H}_{6} \mathrm{O}_{2}$ & $110 \mathrm{~g} / \mathrm{mol}$ & $0.500 \mathrm{mmol} / \mathrm{L}$ & $36.0 \mathrm{mg} / \mathrm{L}$ \\
\hline$p$-benzoquinone & & $\mathrm{C}_{6} \mathrm{H}_{4} \mathrm{O}_{2}$ & $108 \mathrm{~g} / \mathrm{mol}$ & $0.500 \mathrm{mmol} / \mathrm{L}$ & $36.0 \mathrm{mg} / \mathrm{L}$ \\
\hline Adipic acid & & $\mathrm{C}_{6} \mathrm{H}_{10} \mathrm{O}_{4}$ & $146 \mathrm{~g} / \mathrm{mol}$ & $0.500 \mathrm{mmol} / \mathrm{L}$ & $36.0 \mathrm{mg} / \mathrm{L}$ \\
\hline Fumaric acid & & $\mathrm{C}_{4} \mathrm{H}_{4} \mathrm{O}_{4}$ & $116 \mathrm{~g} / \mathrm{mol}$ & $0.500 \mathrm{mmol} / \mathrm{L}$ & $24.0 \mathrm{mg} / \mathrm{L}$ \\
\hline Maleic acid & & $\mathrm{C}_{4} \mathrm{H}_{4} \mathrm{O}_{4}$ & $116 \mathrm{~g} / \mathrm{mol}$ & $0.500 \mathrm{mmol} / \mathrm{L}$ & $24.0 \mathrm{mg} / \mathrm{L}$ \\
\hline Acetic acid & & $\mathrm{C}_{2} \mathrm{H}_{4} \mathrm{O}_{2}$ & $60.1 \mathrm{~g} / \mathrm{mol}$ & $0.500 \mathrm{mmol} / \mathrm{L}$ & $12.0 \mathrm{mg} / \mathrm{L}$ \\
\hline Glyoxylic acid & & $\mathrm{C}_{2} \mathrm{H}_{2} \mathrm{O}_{3}$ & $74.0 \mathrm{~g} / \mathrm{mol}$ & $0.500 \mathrm{mmol} / \mathrm{L}$ & $12.0 \mathrm{mg} / \mathrm{L}$ \\
\hline Oxalic acid & & $\mathrm{C}_{2} \mathrm{H}_{4} \mathrm{O}_{4}$ & $90.0 \mathrm{~g} / \mathrm{mol}$ & $0.500 \mathrm{mmol} / \mathrm{L}$ & $12.0 \mathrm{mg} / \mathrm{L}$ \\
\hline Formic acid & & $\mathrm{CH}_{2} \mathrm{O}_{2}$ & $46.0 \mathrm{~g} / \mathrm{mol}$ & $0.500 \mathrm{mmol} / \mathrm{L}$ & $6.00 \mathrm{mg} / \mathrm{L}$ \\
\hline
\end{tabular}

Acetic acid, adipic acid, $p$-benzoquinone, catechol, formic acid, fumaric acid, glyoxylic acid, maleic acid, and oxalic acid were treated using the apparatus described above, individually. The molecular structures and chemical properties of the compounds that were tested are shown in Table 1. We found that the number of carbon

Table 1. Molecular structures and chemical properties of the test compounds. 
atoms in a compound, the functional groups present, and the presence of a benzene ring affected the TOC removal efficiency that was achieved. Sample solutions containing $0.500 \mathrm{mmol} / \mathrm{dm}^{3}$ of acetic acid, adipic acid, p-benzoquinone, catechol, formic acid, fumaric acid, glyoxylic acid, maleic acid, or oxalic acid were prepared. Each sample solution $\left(1000 \mathrm{~cm}^{3}\right)$ was circulated through the system at a flow rate of $1000 \mathrm{~cm}^{3} / \mathrm{min}$. The air containing ozone that had been generated was fed into the sample solution at a flow rate of $200 \mathrm{~cm}^{3} / \mathrm{min}$. Samples were collected at certain times during a test. The total organic carbon (TOC) content of the solution was determined using a TOC meter (multi N/C2100S; Analytik Jena AG, Jena, Germany).

The effects achieved using five different AOPs $\left(\mathrm{O}_{3}\right.$ alone and UV alone, and the combinations $\mathrm{O}_{3}-\mathrm{UV}$, $\mathrm{UV}-\mathrm{TiO}_{2}$, and $\mathrm{O}_{3}-\mathrm{UV}-\mathrm{TiO}_{2}$ ) were examined. When $\mathrm{O}_{3}$ alone was used, $\mathrm{UV}$ light was intercepted by covering the outside of the inner tube. The $\mathrm{O}_{3}$-UV process was performed by irradiating the sample solution with UV and supplying the solution with ozone. The $\mathrm{O}_{3}-\mathrm{UV}-\mathrm{TiO}_{2}$ process was performed using the outer tube that had been coated with $\mathrm{TiO}_{2}$, supplying ozone, and irradiating the system with UV. Ozone was supplied at a rate of 0.0760 $\mathrm{mg} / \mathrm{min}$ (measured using the iodometric method [32]). No air containing ozone was supplied in the UV alone and $\mathrm{UV}-\mathrm{TiO}_{2}$ process.

\section{Results and Discussion}

\subsection{Removal Efficiencies Using Different AOPs}

The TOC removal efficiencies achieved when catechol and $p$-benzoquinone (both aromatic compounds) were treated using the five different AOPs are shown in Figure 2. The standard deviation was at most $2.66 \%$. The TOC contents of the catechol and $p$-benzoquinone solutions decreased only a little when the solutions were treated using $\mathrm{O}_{3}$ alone, the TOC removal efficiencies being $<10 \%$ in $660 \mathrm{~min}$. This was because too little ozone was supplied (the ozone flow rate was $0.0760 \mathrm{mg} / \mathrm{min}$ ) to decompose the catechol and $p$-benzoquinone effectively. The TOC removal efficiencies achieved in the catechol and $p$-benzoquinone tests were clearly higher when the $\mathrm{O}_{3}$-UV process was used than when UV alone was used. The TOC removal efficiencies achieved in the catechol and $p$-benzoquinone tests were also higher when the $\mathrm{O}_{3}-\mathrm{UV}-\mathrm{TiO}_{2}$ process was used than when the $\mathrm{UV}-\mathrm{TiO}_{2}$ process was used. The catechol TOC removal efficiency after $300 \mathrm{~min}$ was $34.7 \%$ higher when the $\mathrm{O}_{3}$-UV process was used than when UV alone was used, and the catechol TOC removal efficiencies obtained by the $\mathrm{O}_{3}$-UV process and $\mathrm{UV}$ alone for 300 min were about 35.6 times higher than for $\mathrm{O}_{3}$ alone. The $p$-benzoquinone TOC removal efficiency after 300 min was $25.6 \%$ higher when the $\mathrm{O}_{3} \mathrm{UV}$ process was used than when UV alone was used, and the $p$-benzoquinone TOC removal efficiencies obtained by the $\mathrm{O}_{3} \mathrm{UV}$ process and $\mathrm{UV}$ alone for 300 min were about 4.57 times higher than for $\mathrm{O}_{3}$ alone. We concluded that more catechol or $p$-benzoquinone was removed when the $\mathrm{O}_{3}$-UV process was used than when $\mathrm{O}_{3}$ alone was used because $\bullet \mathrm{OH}$ radicals, generated when the ozone was irradiated with UV [33], would have been present during the $\mathrm{O}_{3}$-UV process. We concluded that aromatic compounds could not be effectively decomposed using $\mathrm{O}_{3}$ alone and that it took a long time to decompose aromatic compounds using UV alone. However, aromatic compounds could be more quickly decomposed using a combination of $\mathrm{O}_{3}$ and UV. The catechol TOC removal efficiency after 300 min was $34.0 \%$
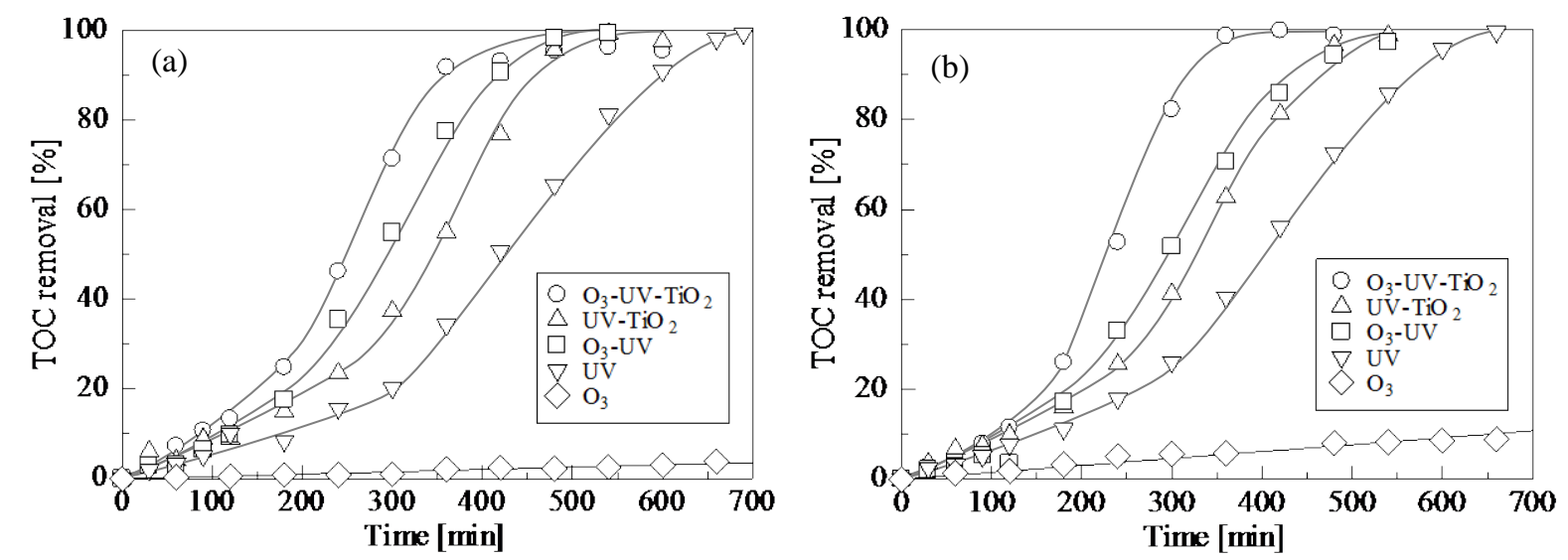

Figure 2. Removal of TOC when the aromatic compounds (a) catechol and (b) p-benzoquinone were treated. 
higher using the $\mathrm{O}_{3}-\mathrm{UV}-\mathrm{TiO}_{2}$ process than using the $\mathrm{UV}-\mathrm{TiO}_{2}$ process, and the catechol TOC removal efficiencies obtained by the $\mathrm{O}_{3}-\mathrm{UV}-\mathrm{TiO}_{2}$ and $\mathrm{UV}-\mathrm{TiO}_{2}$ processes were about 34.9 times higher than for $\mathrm{O}_{3}$ alone. The p-benzoquinone TOC removal efficiency after 300 min was $41.0 \%$ higher using the $\mathrm{O}_{3}-\mathrm{UV}-\mathrm{TiO}_{2}$ process than using the $\mathrm{UV}-\mathrm{TiO}_{2}$ process, and the $p$-benzoquinone TOC removal efficiencies obtained by the $\mathrm{O}_{3}-\mathrm{UV}-\mathrm{TiO}_{2}$ and $\mathrm{UV}-\mathrm{TiO}_{2}$ processes were about 7.31 times higher than for $\mathrm{O}_{3}$ alone. It is possible that more $\bullet \mathrm{OH}$ radicals were generated during the $\mathrm{O}_{3}-\mathrm{UV}-\mathrm{TiO}_{2}$ process than during the $\mathrm{UV}-\mathrm{TiO}_{2}$ process. In addition to the $\bullet \mathrm{OH}$ radicals generated when ozone was irradiated with $\mathrm{UV}$, the presence of both ozone and $\mathrm{TiO}_{2}$ would have promoted the generation of $\bullet \mathrm{OH}$ radicals. Ozone adsorbed onto $\mathrm{TiO}_{2}$ captures electrons, produces ozonide ions, and generates $\bullet \mathrm{OH}$ radicals [33]. Therefore, the presence of $\bullet \mathrm{OH}$ radicals will strongly increase the efficiency at which aromatic compounds will be degraded in an AOP.

The TOC removal efficiencies achieved for maleic acid and oxalic acid (both open-chain compounds) using the five AOPs are shown in Figure 3. The standard deviation was at most 2.92\%. The TOC removal efficiencies achieved using the different AOPs followed different trends for the open-chain compounds and the aromatic compounds. The TOC removal efficiencies for the aromatic compounds decreased in the order $\mathrm{O}_{3}-\mathrm{UV}-\mathrm{TiO}_{2}>$ $\mathrm{O}_{3}-\mathrm{UV}>\mathrm{UV}-\mathrm{TiO}_{2}>\mathrm{UV}$ alone $>\mathrm{O}_{3}$ alone. However, the TOC removal efficiencies for the open-chain compounds decreased in the order $\mathrm{O}_{3}-\mathrm{UV}-\mathrm{TiO}_{2} \approx \mathrm{UV}-\mathrm{TiO}_{2}>\mathrm{O}_{3}-\mathrm{UV}>\mathrm{UV}$ alone $>\mathrm{O}_{3}$ alone. In other words, the TOC removal efficiencies for the aromatic compounds were higher using the $\mathrm{O}_{3}$-UV process than using the $\mathrm{UV}-\mathrm{TiO}_{2}$ process, but the TOC removal efficiencies for the open-chain compounds were higher using the $\mathrm{UV}-\mathrm{TiO}_{2}$ process than using the $\mathrm{O}_{3}$-UV process. The TOC removal efficiencies for the open-chain compounds were about the same when the UV-TiO 2 process and the $\mathrm{O}_{3}-\mathrm{UV}-\mathrm{TiO}_{2}$ process were used, i.e., adding $\mathrm{O}_{3}$ to the UV-TiO ${ }_{2}$ process did not improve the TOC removal efficiencies for the open-chain compounds. It was thought that the improvement of the decomposition efficiency was not observed at $\mathrm{O}_{3}-\mathrm{UV}-\mathrm{TiO}_{2}$ process compared with $\mathrm{UV}-\mathrm{TiO}_{2}$ process because the photocatalytic activity of $\mathrm{TiO}_{2}$ was high enough to decompose the open-chain compounds. In other words, it was considered that the combination of UV and $\mathrm{TiO}_{2}$ was effective against the cleavage of $\mathrm{C}-\mathrm{C}$ bonds in open-chain compounds. The $\mathrm{UV}-\mathrm{TiO}_{2}$ process was one of the most effective methods for degrading open-chain compounds, and using the $\mathrm{UV}^{-\mathrm{TiO}_{2}}$ process could be cheaper than using the $\mathrm{O}_{3}-\mathrm{UV}-\mathrm{TiO}_{2}$ process, because the $\mathrm{UV}-\mathrm{TiO}_{2}$ process does not involve the use of ozone. We therefore concluded that the $\mathrm{UV}-\mathrm{TiO}_{2}$ process was the optimum method for degrading open-chain compounds.

\subsection{Removal Efficiencies for Compounds with Different Structures}

\subsubsection{Influence of the Number of Carbon Atoms}

Adipic acid, formic acid, fumaric acid, maleic acid, and oxalic acid were decomposed using the $\mathrm{O}_{3}-\mathrm{UV}-\mathrm{TiO}_{2}$ process, individually. The results are shown in Figure 4. The standard deviation was at most $2.27 \%$. The TOC removal efficiency increased in the order adipic acid, maleic acid, fumaric acid, oxalic acid, formic acid, i.e., the TOC removal efficiency increased as the number of carbon atoms decreased. Intermediates with fewer carbon atoms would have been formed before the compound was completely decomposed to form $\mathrm{H}_{2} \mathrm{O}$ and $\mathrm{CO}_{2}$. We concluded that the fewer carbon atoms a molecule contained, the faster the molecule was converted into $\mathrm{H}_{2} \mathrm{O}$
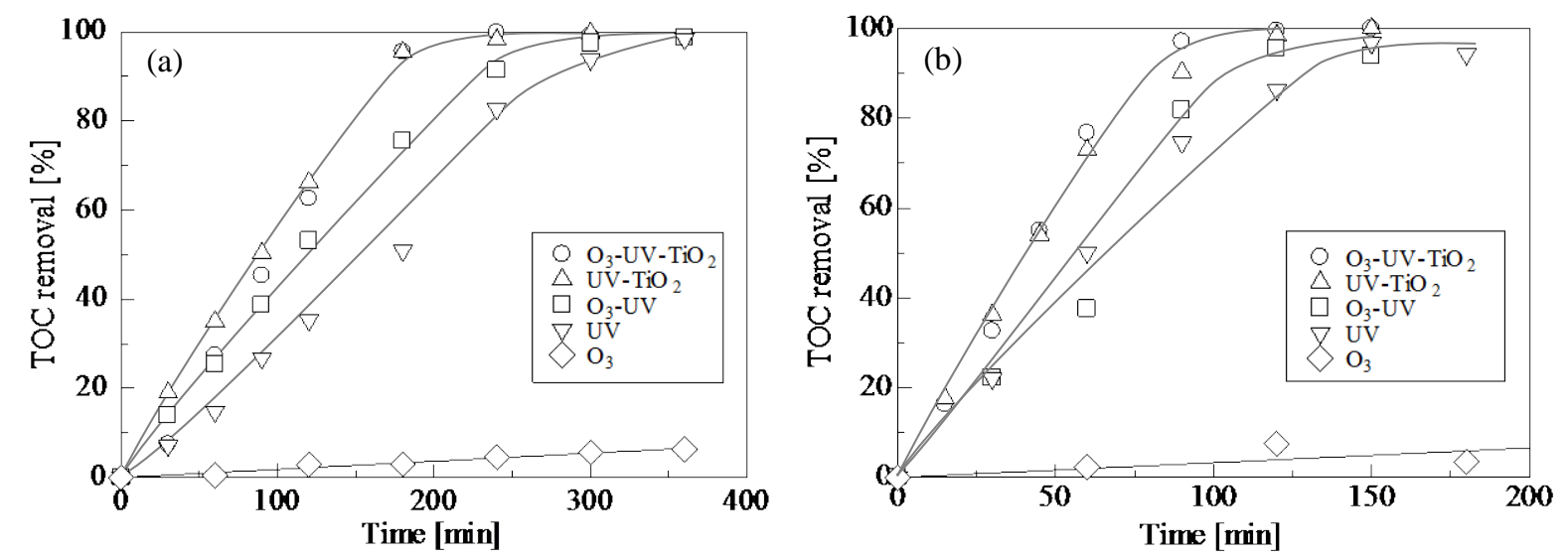

Figure 3. Removal the TOC when the open-chain compounds (a) maleic acid and (b) oxalic acid were treated. 
and $\mathrm{CO}_{2}$ (i.e., the TOC was removed more quickly as the number of carbon atoms decreased). Lesko et al. [34] studied the kinetics of the degradation of phenol (as TOC) in an $\mathrm{O}_{3}$-ultrasound process. They reported that a plot of $[\mathrm{TOC}] /[\mathrm{TOC}]_{0}$, where $[\mathrm{TOC}]_{0}$ is the initial TOC value, against the reaction time when phenol was degraded gave a straight line, i.e., the degradation of the TOC in the phenol tests followed pseudo-zero-order kinetics. We assumed that the degradation of the TOC when adipic acid, fumaric acid, maleic acid, oxalic acid, and formic acid were treated using the $\mathrm{O}_{3}-\mathrm{UV}-\mathrm{TiO}_{2}$ process followed pseudo-zero-order reaction kinetics. Plots of our $[\mathrm{TOC}] /[\mathrm{TOC}]_{0}$ values against the reaction time are shown in Figure 5 . The pseudo-zero-order rate constants and the linear correlation coefficients $\left(R^{2}\right)$ for the removal of the TOC when adipic acid, fumaric acid, maleic acid, oxalic acid, and formic acid were treated are shown in Table 2. The correlation coefficients for the pseudo-zero-order rate constants that were calculated were all $>0.955$. These results confirmed that the removal of the TOC when organic compounds were treated using the $\mathrm{O}_{3}-\mathrm{UV}-\mathrm{TiO}_{2}$ process in our tests followed pseudozero-order kinetics. The TOC degradation rate constants are plotted against the number of carbon atoms in the molecules in Figure 6. The curve was fitted with an exponential function, and this gave an $R^{2}$ value of 0.995. These results confirmed that there was an exponential relationship $\left(y=0.0239 e^{-0.366 x}\right)$ between the number of carbon atoms in a molecule and the TOC degradation rate constant for compounds with the same functional group.

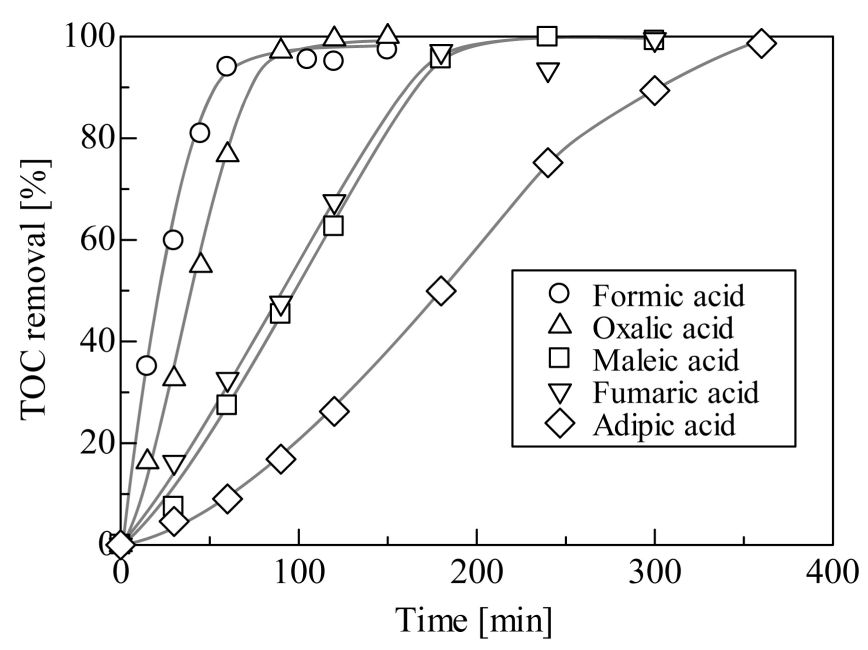

Figure 4. Removal of the TOC when compounds containing different numbers of carbon atoms were treated.

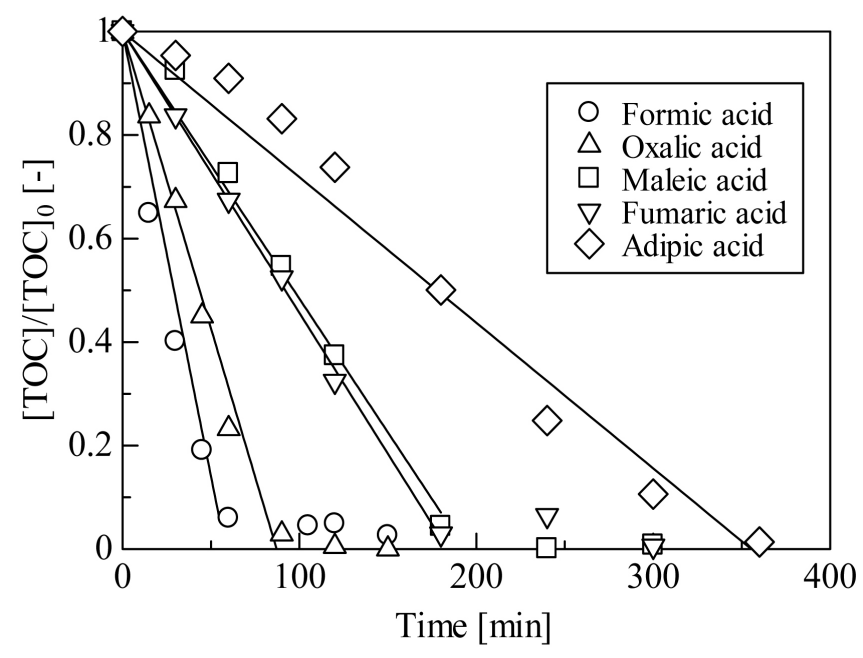

Figure 5. Changes in the $[\mathrm{TOC}] /[\mathrm{TOC}]_{0}$ ratio over time when compounds containing different numbers of carbon atoms were treated. 


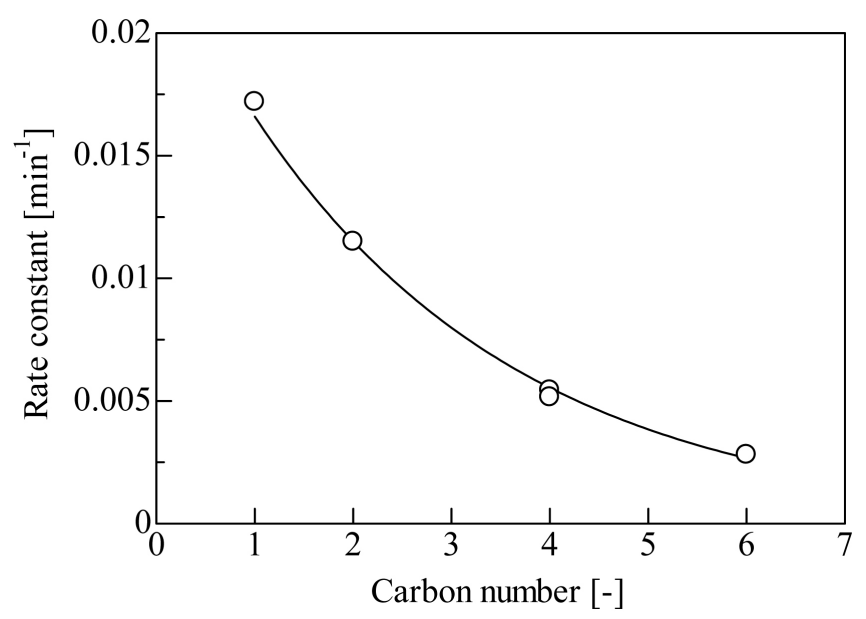

Figure 6. Relationship between the number of carbon atoms and the rate constant.

Table 2. Rate constants and $R^{2}$ values for the removal of the TOC of open-chain compounds using the $\mathrm{O}_{3}-\mathrm{UV}-\mathrm{TiO}_{2}$ process.

\begin{tabular}{cccc}
\hline Sample & Number of carbon atom & $k\left[\mathrm{~min}^{-1}\right]$ & $R^{2}$ \\
\hline Adipic acid & 6 & 0.00281 & 0.975 \\
Maleic acid & 4 & 0.00516 & 0.987 \\
Fumaric acid & 4 & 0.00544 & 0.999 \\
Oxalic acid & 2 & 0.0115 & 0.983 \\
Formic acid & 1 & 0.0172 & 0.955 \\
\hline
\end{tabular}

\subsubsection{Influence of the Functional Group}

The TOC removal efficiencies achieved for acetic acid, glyoxylic acid, and oxalic acid using the $\mathrm{O}_{3}-\mathrm{UV}-\mathrm{TiO}_{2}$ process and plots of the $[\mathrm{TOC}] /[\mathrm{TOC}]_{0}$ values against the reaction time are shown in Figure 7 . The standard deviation was at most $1.98 \%$. Acetic acid, glyoxylic acid, and oxalic acid are carboxylic acids with two carbon atoms. One of the functional groups in acetic acid, glyoxylic acid, and oxalic acid is a methyl group, an aldehyde group and a carboxyl group, respectively. The TOC degradation rate constants for acetic acid, glyoxylic acid, and oxalic acid were $0.00604,0.00843$, and $0.0115 \mathrm{~min}^{-1}$, respectively, i.e., the rate at which the TOC was removed increased in the order oxalic acid, glyoxylic acid, acetic acid. Sillanpää et al. [26] reported that glyoxylic acid was converted into oxalic acid when EDTA was decomposed using an AOP. The rate constant was lower for the degradation of glyoxylic acid than for the degradation of oxalic acid in our study, and this could have been because glyoxylic acid was oxidized to give oxalic acid. The rate constant was lower for the degradation of acetic acid than for the degradation of glyoxylic acid, and this could have been because acetic acid was oxidized to give glyoxylic acid. The possible pathway for the degradation of organic compounds with two carbon atoms during the $\mathrm{O}_{3}-\mathrm{UV}-\mathrm{TiO}_{2}$ process is shown in Figure 8.

\subsubsection{Influence of the Presence of a Benzene ring}

The TOC removal efficiencies achieved for catechol, $p$-benzoquinone, and adipic acid using the $\mathrm{O}_{3}-\mathrm{UV}-\mathrm{TiO}_{2}$ process are shown in Figure 9. The standard deviation was at most 1.27\%. Each of these compounds contains six carbon atoms. The TOC was clearly removed more quickly in the initial stages of the reaction when adipic acid was treated than when catechol and $p$-benzoquinone were treated. Benzene rings were degraded less effectively than C-C bonds, and this would have been because a benzene ring will generally be more stable than a $\mathrm{C}-\mathrm{C}$ bond. The $[\mathrm{TOC}] /[\mathrm{TOC}]_{0}$ values are plotted against the reaction time in Figure 10. Two different rate constants were found for the removal of the TOC when aromatic compounds were treated. The rate constant for catechol was $0.00127 \mathrm{~min}^{-1}$ for the first $180 \mathrm{~min}$, and the degradation process continued to follow pseudo-zeroorder kinetics but at a faster rate $\left(k=0.00376 \mathrm{~min}^{-1}\right)$ after $180 \mathrm{~min}$. The results for $p$-benzoquinone were similar 

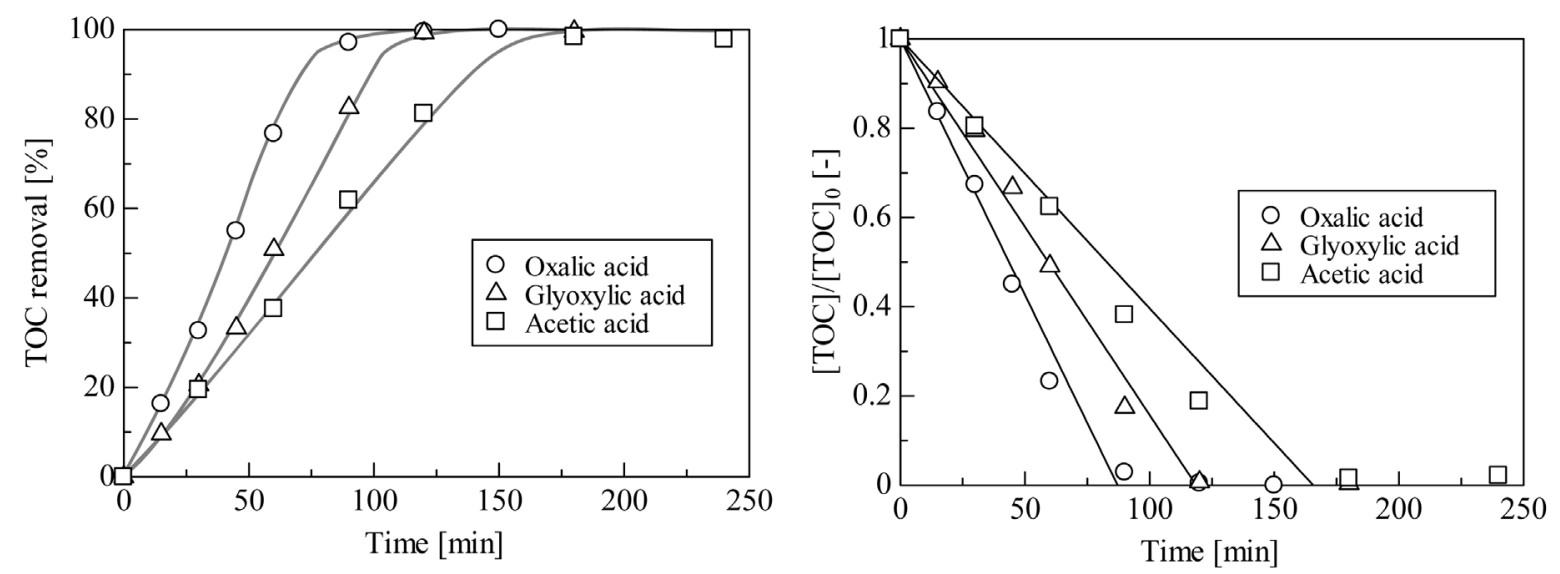

Figure 7. Removal of the TOC and changes in the $[\mathrm{TOC}] /[\mathrm{TOC}]_{0}$ ratio over time when compounds with different functional groups were treated.

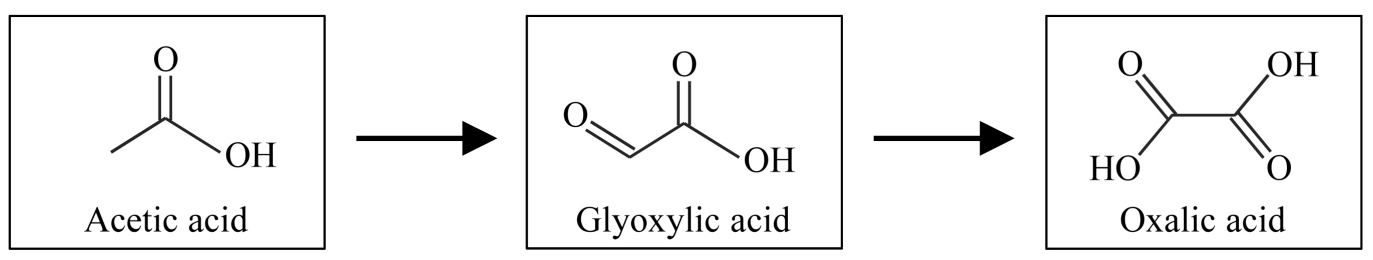

Figure 8. Degradation pathway for an organic compound containing two carbon atoms during the $\mathrm{O}_{3}-\mathrm{UV}-\mathrm{TiO}_{2}$ process.

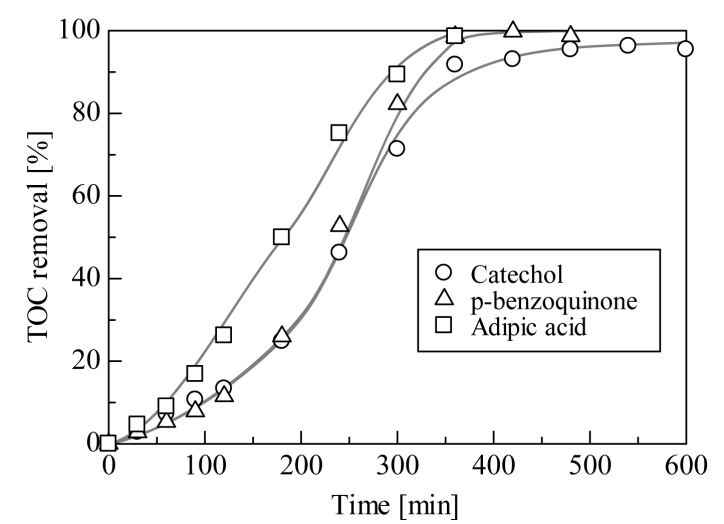

Figure 9. Removal of the TOC when aromatic compounds (catechol and p-benzoquinone) and an open-chain compound (adipic acid) were treated.

to the results for catechol, the $p$-benzoquinone rate constant being $0.000927 \mathrm{~min}^{-1}$ for the first $145 \mathrm{~min}$, then $0.00412 \mathrm{~min}^{-1}$ (still following pseudo-zero-order kinetics). It has previously been reported that open-chain compounds are generated when aromatic compounds decompose [34]-[36]. It could therefore be concluded that benzene rings were cleaved to generate open-chain compounds in the first stage of the degradation process, and then that the open-chain compounds generated decomposed in the second stage. It is more difficult to cleave a benzene ring than a C-C bond, and the TOC concentration in the sample solution changed only a little in the first stage of the degradation process. This explained why the rate constant was lower for the first stage than for the second stage of the degradation process.

We believe that almost all of the benzene rings had been cleaved by the end of the first stage of the degradation process. The rate constants for the second stage were between the rate constants for adipic acid $(0.00280$ $\left.\mathrm{min}^{-1}\right)$ and maleic acid $\left(0.00516 \mathrm{~min}^{-1}\right)$. We assume that adipic acid and maleic acid were generated in the proportions $x \%$ and $y \%$, respectively, by the end of the first stage. The rate constants for catechol, adipic acid, and maleic acid were used to calculate $x_{1}$ and $y_{1}$ values for catechol, and the $x_{1}$ and $y_{1}$ values that were found were 

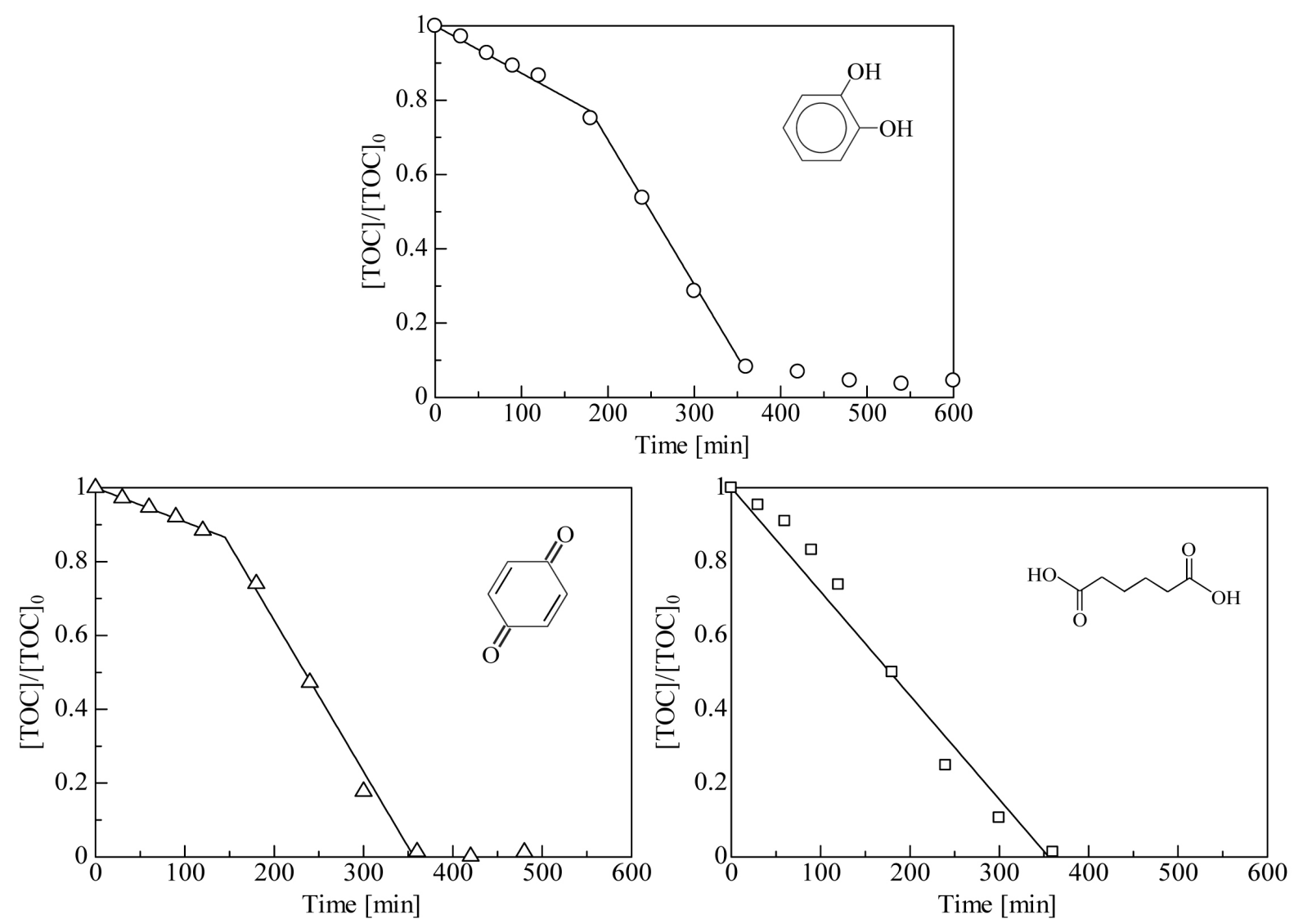

Figure 10. Changes in the $[\mathrm{TOC}] /[\mathrm{TOC}]_{0}$ ratio over time when catechol, $p$-benzoquinone, and adipic acid were treated using the $\mathrm{O}_{3}-\mathrm{UV}-\mathrm{TiO}_{2}$ process.

59.3 and 40.7, respectively. These values indicated that $59.3 \%$ adipic acid and $40.7 \%$ maleic acid had been generated by the end of the initial stage of the catechol degradation process. Treating the $p$-benzoquinone results in the same way indicated that $44.1 \%$ adipic acid and $55.9 \%$ maleic acid had been generated by the end of the first stage of the $p$-benzoquinone degradation process.

\section{Conclusions}

The effects of AOPs on the decomposition properties of organic compounds with different chemical structures were confirmed in this study.

It is necessary to use an $\mathrm{O}_{3}-\mathrm{UV}-\mathrm{TiO}_{2}$ process to decompose compounds containing benzene rings as quickly as possible. However, the TOC was removed at a similar rate when open-chain compounds were treated using the $\mathrm{O}_{3}-\mathrm{UV}-\mathrm{TiO}_{2}$ and $\mathrm{UV}-\mathrm{TiO}_{2}$ processes. We therefore conclude that the $\mathrm{UV}-\mathrm{TiO}_{2}$ process degraded the open-chain compounds most effectively, and that the $\mathrm{O}_{3}-\mathrm{UV}-\mathrm{TiO}_{2}$ process did not need to be used to decompose open-chain compounds.

The TOC was removed more slowly when aromatic compounds were treated than when open-chain compounds were treated. The TOC removal efficiency increased as the number of carbon atoms in the molecule being treated decreased. Organic compounds containing carboxyl groups were more easily decomposed than compounds containing aldehyde groups, and compounds containing aldehyde groups were more easily decomposed than compounds containing methyl groups. The removal of the TOC when organic compounds were treated using the $\mathrm{O}_{3}-\mathrm{UV}-\mathrm{TiO}_{2}$ process followed pseudo-zero-order kinetics.

\section{Acknowledgements}

This research was supported by the Japanese Ministry of Education, Culture, Sports, Science and Technology 
(MEXT) Supported Program for the Strategic Research at Private Universities, 2012-2016, and by a Kansai University grant-in-aid for the promotion and improvement of education and research, 2014, "Development of inorganic membranes and membrane reactor using inorganic membranes”.

\section{References}

[1] Takahashi, M., Ohya, A., Kawakami, S., Yoneyama, Y., Onodera, T., Syutsubo, K., Yamazaki, S., Araki, N., Ohashi, A., Harada, H. and Yamaguchi, T. (2011) Evaluation of Treatment Characteristics and Sludge Properties in a UASB Reactor Treating Municipal Sewage at Ambient Temperature. International Journal of Environmental Research, 5, 821-826.

[2] He, Z., Song, S., Xia, M., Qiu, J., Ying, H., Lü, B., Jiang, Y. and Chen, J. (2008) Mineralization of C.I. Reactive Blue 19 by Ozonation Combined with Sonolysis: Performance Optimization and Degradation Mechanism. Separation and Purification Technology, 62, 376-381. http://dx.doi.org/10.1016/j.seppur.2008.02.005

[3] Kurniawa, T.A. and Lo, W.-H. (2009) Removal of Refractory Compounds from Stabilized Landfill Leachate Using an Integrated $\mathrm{H}_{2} \mathrm{O}_{2}$ Oxidation and Granular Activated Carbon (GAC) Adsorption Treatment. Water Research, 43, 40794091. http://dx.doi.org/10.1016/j.watres.2009.06.060

[4] Pocostales, J.P., Sein, M.M., Knolle, W., von Sonntag, C. and Schmidt, T.C. (2010) Degradation of Ozone-Refractory Organic Phosphates in Wastewater by Ozone and Ozone/Hydrogen Peroxide (Peroxone): The Role of Ozone Consumption by Dissolved Organic Matter. Environmental Science\& Technology, 44, 8248-8253. http://dx.doi.org/10.1021/es1018288

[5] Nasuhoglu, D., Rodayan, A., Berk, D. and Yargeau, V. (2012) Removal of the Antibiotic Levofloxacin (LEVO) in Water by Ozonation and $\mathrm{TiO}_{2}$ Photocatalysis. Chemical Engineering Journal, 189-190, 41-48. http://dx.doi.org/10.1016/j.cej.2012.02.016

[6] Kümmerer, K., Al-Ahmad, A. and Mersch-Sundermann, V. (2000) Biodegradability of Some Antibiotics, Elimination of the Genotoxicity and Affection of Wastewater Bacteria in a Simple Test. Chemosphere, 40, 701-710. http://dx.doi.org/10.1016/S0045-6535(99)00439-7

[7] Glaze, W.H., Kang, J.W. and Chapin, D.H. (1987) The Chemistry of Water Treatment Processes Involving Ozone, Hydrogen Peroxide and Ultraviolet Radiation. Ozone: Science \& Engineering, 9, 335-352. http://dx.doi.org/10.1080/01919518708552148

[8] Kurniawan, T.A., Lo, W.-H. and Chan, G.Y.S. (2006) Radicals-Catalyzed Oxidation Reactions for Degradation of Recalcitrant Compounds from Landfill Leachate. Chemical Engineering Journal, 125, 35-57. http://dx.doi.org/10.1016/j.cej.2006.07.006

[9] Lucas, M.S., Peres, J.A. and Puma, G.L. (2010) Treatment of Winery Wastewater by Ozone-Based Advanced Oxidation Processes $\left(\mathrm{O}_{3}, \mathrm{O}_{3} / \mathrm{UV}\right.$ and $\left.\mathrm{O}_{3} / \mathrm{UV} / \mathrm{H}_{2} \mathrm{O}_{2}\right)$ in a Pilot-Scale Bubble Column Reactor and Process Economics. Separation and Purification Technology, 72, 235-241. http://dx.doi.org/10.1016/j.seppur.2010.01.016

[10] Iwaguch, S., Matsumura, K., Tokuoka, Y., Wakui, S. and Kawashima, N. (2002) Sterilization System Using Microwave and UV Light. Colloids and Surfaces B: Biointerfaces, 25, 299-304. http://dx.doi.org/10.1016/S0927-7765(01)00324-1

[11] Hsieh, F.-C., Lou, J.-C. and Chiou, C.-S. (2009) Use of UV/O ${ }_{3}$ to Aqueous Mineralize N-methyl-2-pyrrolidinone. Practice Periodical of Hazardous, Toxic, and Radioactive Waste Management, 13, 120-125. http://dx.doi.org/10.1061/(ASCE)1090-025X(2009)13:2(120)

[12] Kishimoto, N., Morita, Y., Tsun, H. and Yasuda, Y. (2007) Characteristics of Electrolysis, Ozonation, and Their Combination Process on Treatment of Municipal Wastewater. Water Environment Research, 79, 1033-1042. http://dx.doi.org/10.2175/106143007X184023

[13] Sánchez, L., Peral, J. and Domenech, X. (1998) Aniline Degradation by Combined Photocatalysis and Ozonation. Applied Catalysis B: Environmental, 19, 59-65. http://dx.doi.org/10.1016/S0926-3373(98)00058-7

[14] Martins, A.F., Henriques, D.M., Wilde, M.L. and Vasconcelos, T.G. (2006) Advanced Oxidation Processes in the Treatment of Trifluraline Effluent. Journal of Environmental Science and Health Part B: Pesticides Food Contaminants and Agricultural Wastes, 41, 245-252. http://dx.doi.org/10.1080/03601230500354782

[15] Qiang, Z., Chang, J.-H. and Huang, C.-P. (2003) Electrochemical Rregeneration of Fe ${ }^{2+}$ in Fenton Oxidation Processes. Water Research, 37, 1308-1319. http://dx.doi.org/10.1016/S0043-1354(02)00461-X

[16] Panizza, M. and Cerisola, G. (2009) Electro-Fenton Degradation of Synthetic Dyes. Water Research, 43, 339-344. http://dx.doi.org/10.1016/j.watres.2008.10.028

[17] Puspita, P., Roddick, F. and Porter, N. (2015) Efficiency of Sequential Ozone and UV-Based Treatments for the Treatment of Secondary Effluent. Chemical Engineering Journal, 268, 337-347. 
http://dx.doi.org/10.1016/j.cej.2015.01.077

[18] Rao, Y.F. and Chu, W. (2009) A New Approach to Quantify the Degradation Kinetics of Linuron with UV, Ozonation and $\mathrm{UV} / \mathrm{O}_{3}$ Processes. Chemosphere, 74, 1444-1449. http://dx.doi.org/10.1016/j.chemosphere.2008.12.012

[19] Homlok, R., Takács, E. and Wojnárovits, L. (2013) Degradation of Organic Molecules in Advanced Oxidation Processes: Relation between Chemical Structure and Degradability. Chemosphere, 91, 383-389. http://dx.doi.org/10.1016/j.chemosphere.2012.11.073

[20] Huang, W., Ren, T. and Xia, W. (2007) Ozone Generation by Hybrid Discharge Combined with Catalysis. Ozone: Science \& Engineering, 29, 107-112. http://dx.doi.org/10.1080/01919510601186527

[21] Abramović, B.F., Banić, N.D. and Šojić, D.V. (2010) Degradation of Thiacloprid in Aqueous Solution by UV and $\mathrm{UV} / \mathrm{H}_{2} \mathrm{O}_{2}$ Treatments. Chemosphere, 81, 114-119. http://dx.doi.org/10.1016/j.chemosphere.2010.07.016

[22] Abouzlam, M., Ouvrard, R., Mehdi, D., Pontlevoy, F., Gombert, B., Leitner, N.K.V. and Boukari, S. (2013) An Optimal Control of a Wastewater Treatment Reactor by Catalytic Ozonation. Control Engineering Practice, 21, 105-112. http://dx.doi.org/10.1016/j.conengprac.2012.09.016

[23] Krivolutsky, A.A. (2011) Ozone Variability of Long-Term Scale near Polar Regions and its Connection to Basic Atmospheric Condition. Advances in Space Research, 28, 971-980. http://dx.doi.org/10.1016/S0273-1177(01)80026-0

[24] Velasco, R.M., Uribe, F.J. and Pérez-Chavela, E. (2008) Stratospheric Ozone Dynamics According to the Chapman Mechanism. Journal of Mathematical Chemistry, 44, 529-539. http://dx.doi.org/10.1007/s10910-007-9326-7

[25] Ince, N.H. and Tezcanlí, G. (2001) Reactive Dyestuff Degradation by Combined Sonolysis and Ozonation. Dyes and Pigments, 49, 145-153. http://dx.doi.org/10.1016/S0143-7208(01)00019-5

[26] Sillanpää, M.E.T., Kurniawan, T.A. and Lo, W.-H. (2011) Degradation of Chelating Agents in Aqueous Solution Using Advanced Oxidation Process (AOP).Chemosphere, 83, 1443-1460. http://dx.doi.org/10.1016/j.chemosphere.2011.01.007

[27] Huang, C.-R. and Shu, H.-Y. (1995) The Reaction Kinetics, Decomposition Pathways and Intermediate Formations of Phenol in Ozonation, $\mathrm{UV} / \mathrm{O}_{3}$ and $\mathrm{UV} / \mathrm{H}_{2} \mathrm{O}_{2}$ Processes. Journal of Hazardous Materials, 41, 47-64. http://dx.doi.org/10.1016/0304-3894(94)00093-V

[28] Vijayalakshmi, P., Bhaskar Raju, G. and Gnanamani, A. (2011) Advanced Oxidation and Electrooxidation as Tertiary Treatment Techniques to Improve the Purity of Tannery Wastewater. Industrial \& Engineering Chemistry Research, 50, 10194-10200. http://dx.doi.org/10.1021/ie201039z

[29] Mahamuni, N.N. and Adewuyi, Y.G. (2010) Advanced Oxidation Processes (AOPs) Involving Ultrasound for Waste Water Treatment: A Review with Emphasis on Cost Estimation. Ultrasonics Sonochemistry, 17, 990-1003. http://dx.doi.org/10.1016/j.ultsonch.2009.09.005

[30] Bai, C., Xiong, X., Gong, W., Feng, D., Xian, M., Ge, Z. and Xu, N. (2011) Removal of Rhodamine B by OzoneBased Advanced Oxidation Process. Desalination, 278, 84-90. http://dx.doi.org/10.1016/j.desal.2011.05.009

[31] Nishimura, A., Komatsu, N., Mitsui, G., Hirota, M. and Hu, E. (2009) $\mathrm{CO}_{2}$ Reforming into Fuel Using TiO $\mathrm{Photoca-}$ talyst and Gas Separation Membrane. Catalysis Today, 148, 341-349. http://dx.doi.org/10.1016/j.cattod.2009.07.067

[32] Beltrán, F.J., Rivas, F.J. and Gimeno, O. (2005) Comparison between Photocatalytic Ozonation and Other Oxidation Processes for the Removal of Phenols from Water. Journal of Chemical Technology and Biotechnology, 80, 973-984. http://dx.doi.org/10.1002/jctb.1272

[33] Suzuki, H., Araki, S. and Yamamoto, H. (2015) Evaluation of Advanced Oxidation Processes (AOP) Using $\mathrm{O}_{3}$, UV, andTiO ${ }_{2}$ for the Degradation of Phenol in Water. Journal of Water Process Engineering, 7, 54-60. http://dx.doi.org/10.1016/j.jwpe.2015.04.011

[34] Lesko, T., Colussi, A.J. and Hoffmann, M.R. (2006) Sonochemical Decomposition of Phenol: Evidence for a Synergistic Effect of Ozone and Ultrasound for the Elimination of Total Organic Carbon from Water. Environmental Science Technology, 40, 6818-6823. http://dx.doi.org/10.1021/es052558i

[35] Dai, Q., Wang, J., Yu, J., Chen, J. and Chen, J. (2014) Catalytic Ozonation for the Degradation of Acetylsalicylic Acid Inaqueous Solution by Magnetic $\mathrm{CeO}_{2}$ Nanometer Catalyst Particles. Applied Catalysis B: Environmental, 144, 686693. http://dx.doi.org/10.1016/j.apcatb.2013.05.072

[36] Yang, L.P., Hu, W.Y., Huang, H.M. and Yan, B. (2010) Degradation of High Concentration Phenol by Ozonation in Combination with Ultrasonic Irradiation. Desalination and Water Treatment, 21, 87-95.

http://dx.doi.org/10.5004/dwt.2010.1233 


\section{Submit or recommend next manuscript to SCIRP and we will provide best service for you:}

Accepting pre-submission inquiries through Email, Facebook, LinkedIn, Twitter, etc.

A wide selection of journals (inclusive of 9 subjects, more than 200 journals)

Providing 24-hour high-quality service

User-friendly online submission system

Fair and swift peer-review system

Efficient typesetting and proofreading procedure

Display of the result of downloads and visits, as well as the number of cited articles

Maximum dissemination of your research work

Submit your manuscript at: http://papersubmission.scirp.org/ 